\title{
A Computational Study on the Kinetic Stability of Cyclic Boryl Anions
}

\author{
Chin-Hung Lai and Pi-Tai Chou*
}

Department of Chemistry, National Taiwan University, 106, Taipei, Taiwan

\begin{abstract}
In this study, we perform an MPW1K investigation on the kinetic stability of a cyclic boryl anion. According to our calculation, the bulkier the $\mathrm{R}$ and $\mathrm{R}$ ' groups are, the more kinetically stable a five-membered boryl anion may be. Nitrogen should be a more efficient $\pi$ donor to increase the kinetic stability of a cyclic boryl anion than P, As, O, S and Se. Although, one nitrogen atom is enough to stabilize a cyclic boryl anion from the kinetic aspect, the stability of a cyclic boryl anion increases as the number of nitrogen in the ring increases. The six-membered boryl anion is calculated to be more stable kinetically than the five-membered one that has been synthesized successfully.
\end{abstract}

\section{INTRODUCTION}

Although boron sits just left to the carbon on the periodic table, this atom does not share its neighbor's reactive versatility. Due to its empty p orbital, which is in contrast to the partially filled $\mathrm{p}$ orbital in carbon, boron compounds are almost found to be electrophilic; i.e. they act as a Lewis acid and are ready to accept electrons from others, during the reaction. In one approach, anionic organoboron alkali metal salts, were reported as possible reactive intermediates in some reactions [1], but none could be isolated or conclusively characterized [2]. In 1995, Schleyer and coworkers, on the basis of theoretical calculation, predicted that diamino groups on the boron atom should stabilize a boryllithium [3]. The stabilization mainly results from the interaction between the empty $\mathrm{p}$ orbital of boron and the lone pair $/ \mathrm{p}_{\pi}$ orbital of the nitrogen atoms. In 2006, Nozaki, Yamashita and Segawa, firstly utilized a boron-bromide precursor to synthesize a stable diaminosubstituted boryllithium (see the upper part of Scheme 1). Xray crystallography and ${ }^{11} \mathrm{~B}$ NMR spectroscopy of the compound matched with the prediction of a boron anion [4].

Boryllithium can be used to synthesize new boroncontaining compounds or to provide a different synthetic route from the traditional ones. For example, boryllithium behaves as an efficient nucleophile when it reacts with the electrophiles such as water, methyltrifluoromethanesulfonate, 1-chlorobutane, and benzaldehyde [4]. Very recently, Segawa and coworkers synthesized a borylmagnesium that may be served as a boron-containing Grignard reagent [5]. In another approach, boryllithium may act as a nucleophile and attack on Group 11 metal chloride complexes. On this basis, Segawa and coworkers reported the examples of borylsilver and borylgold complexes [6].

Traditionally, the methodologies to introduce a boryl ligand into a transition-metal complex can be classified into three types of reactions: 1) salt elimination through the reaction of anionic metal carbonyl complexes with haloboranes [7]; 2) oxidative addition of a boron-heteroatom bond

*Address correspondence to this author at the Department of Chemistry, National Taiwan University, 106, Taipei, Taiwan; E-mail: chop@ntu.edu.tw to low-valent transition metals [8], and 3) $\sigma$-bond metathesis reactions between alkyl metal complexes and hydroboranes in the presence of light or oxygen-substituted metal complexes and diborane [9-11].

Herein, we report a computational study on the kinetic stability of cyclic boryl anions. The effects of substituents ( $R$ and R') and types of atoms in the ring $\left(X_{1}, X_{2}, X_{3}\right.$ and $X_{4}$ in Scheme 1) are investigated. Currently available cyclic boryl anions possess a five-membered ring $[4,6]$, which is isoelectronic with the five-membered $\mathrm{N}$-heterocyclic carbine (NHC) [12]. Five-membered N-heterocyclic carbines (NHCs) are widely used in catalysis [12-14]. Nevertheless, their four-, six-and seven-membered analogs have been synthesized and showed marked different electronic structures from that of the five-membered analogues [15-17]. Thus, it is also important to investigate the cyclic boryl anions other than five membered ones, although, they are synthetically unattainable at this stage. Accordingly, in addition to fivemembered boryl anions (1-4), the four-, six-and sevenmembered analogs (5-7 in Scheme 1) are also taken into consideration. Furthermore, the effects of additional aromatic rings on $\mathbf{6}$ and $\mathbf{7}$ denoted by $\mathbf{8}$ and $\mathbf{9}$, are also studied, respectively.

\section{THEORETICAL BASIS}

All calculations are done with the Gaussian 03 program [18]. Four DFT functionals, i.e. B3LYP, MPWB1K, MPW1B95 and MPW1K are chose; and combined with the double- $\zeta$ basis set $6-31+\mathrm{G}^{*}$, in this study [19-22]. The 1,2-R or R' shifted isomerization reaction ( $\mathrm{R}$ and $\mathrm{R}^{\prime}=\mathrm{H}, \mathrm{CH}_{3}$ and $\mathrm{Ph}$ ) is chosen for the comparative studies of the kinetic stability. These reactions can be expressed as Eq. (1):

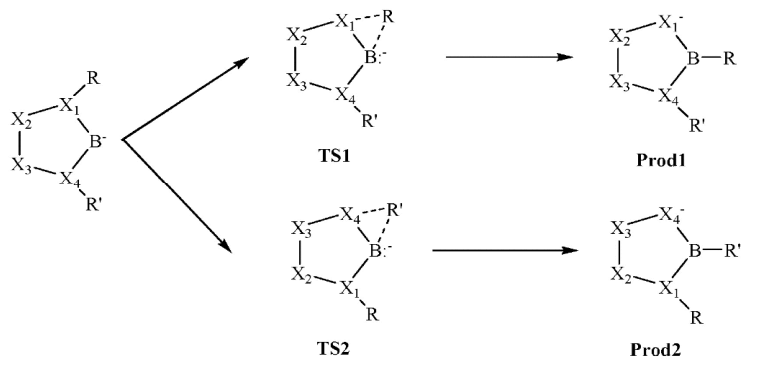


All three points of interest, including reactants, transition states (TS), and products on the potential energy surfaces (PES) of the isomerization reactions, have been investigated. All stationary points have been positively identified as equilibrium structures (the numbers of imaginary frequency $(\mathrm{NIMAG}=0)$ ), or transition states $(\mathrm{NIMAG}=1)$. For the transition states, motion corresponding to the imaginary frequency is checked visually. All mentioned energetic values are corrected for zero point energies (ZPE). To aid in the experimental characterization of such anions, the ${ }^{11} \mathrm{~B}$ chemical tensor of each minimum is calculated by the gaugeindependent atomic orbitals (GIAO) method [23]. Theoretically, the chemical shielding depends on the orientation of the molecule, in relation to the applied magnetic field. Therefore, the chemical shielding can be described by a ninecomponent cartesian tensor, $\sigma$.

$$
\sigma=\left[\begin{array}{lll}
\sigma_{11} & \sigma_{12} & \sigma_{13} \\
\sigma_{21} & \sigma_{22} & \sigma_{23} \\
\sigma_{31} & \sigma_{32} & \sigma_{33}
\end{array}\right]
$$

Unfortunately, in conventional NMR experiments, the trace of the tensor can only be determined. Then the isotropic chemical shielding, $\sigma^{\text {iso }}$, is defined as (3)

$$
\sigma^{i s o}=\frac{1}{3}\left(\sigma_{11}+\sigma_{22}+\sigma_{33}\right)
$$

Usually, the calculated chemical tensor of a compound is reported in relation with a reference. Thus, the complex $\mathrm{BF}_{3}: \mathrm{OEt}_{2}$ is taken as the standard of ${ }^{11} \mathrm{~B}$ chemical tensor. The solvent effect of tetrahydrofuran (THF) and acetonitrile is considered by a single-point MPW1K-PCM calculation [24].

\section{RESULTS AND DISCUSSION}

\section{The Performance of DFT Functional}

The results of isomerization reaction of 1a using four different DFT functionals, are summarized in Table 1. As shown in Table 1, although the MPW1K functional underestimates the isomerization barrier of $\mathbf{1 a}$ by $70.70 \mathrm{~kJ} / \mathrm{mol}$, its average deviation is the smallest among the tested DFT functionals as compared with the previous MP4 result [25]. Therefore, we believe that MPW1K should provide a decent analysis for those boryl anions depicted in Scheme $\mathbf{1}$.

Table 1. The Activation Energies $\left(E_{a}\right.$ in $\left.\mathbf{k J} / \mathbf{m o l}\right)$, Reaction Enthalpies $\left(\Delta H_{r}\right.$ in $\left.\mathrm{kJ} / \mathrm{mol}\right)$ of the Isomerization Reaction of 1 a

\begin{tabular}{|c|c|c|c|c|c|}
\hline & B3LYP & MPWB1K & MPW1B95 & MPW1K & The Previous Results \\
\hline \hline $\mathrm{E}_{\mathrm{a}}$ & 117.2 & 115.7 & 124.0 & 127.5 & $198.2^{\mathrm{a}}$ \\
\hline$\Delta \mathrm{H}_{\mathrm{r}}$ & -185.3 & -185.6 & -186.8 & -186.2 & $\begin{array}{l}-175.6^{\mathrm{a}} \\
-178.1^{\mathrm{b}}\end{array}$ \\
\hline
\end{tabular}

a. The MP4/6-311+G*//HF/6-311+G* results in ref. [25].

b. The B3LYP/6-31++G(d,p)+ZPE results in ref. [26].
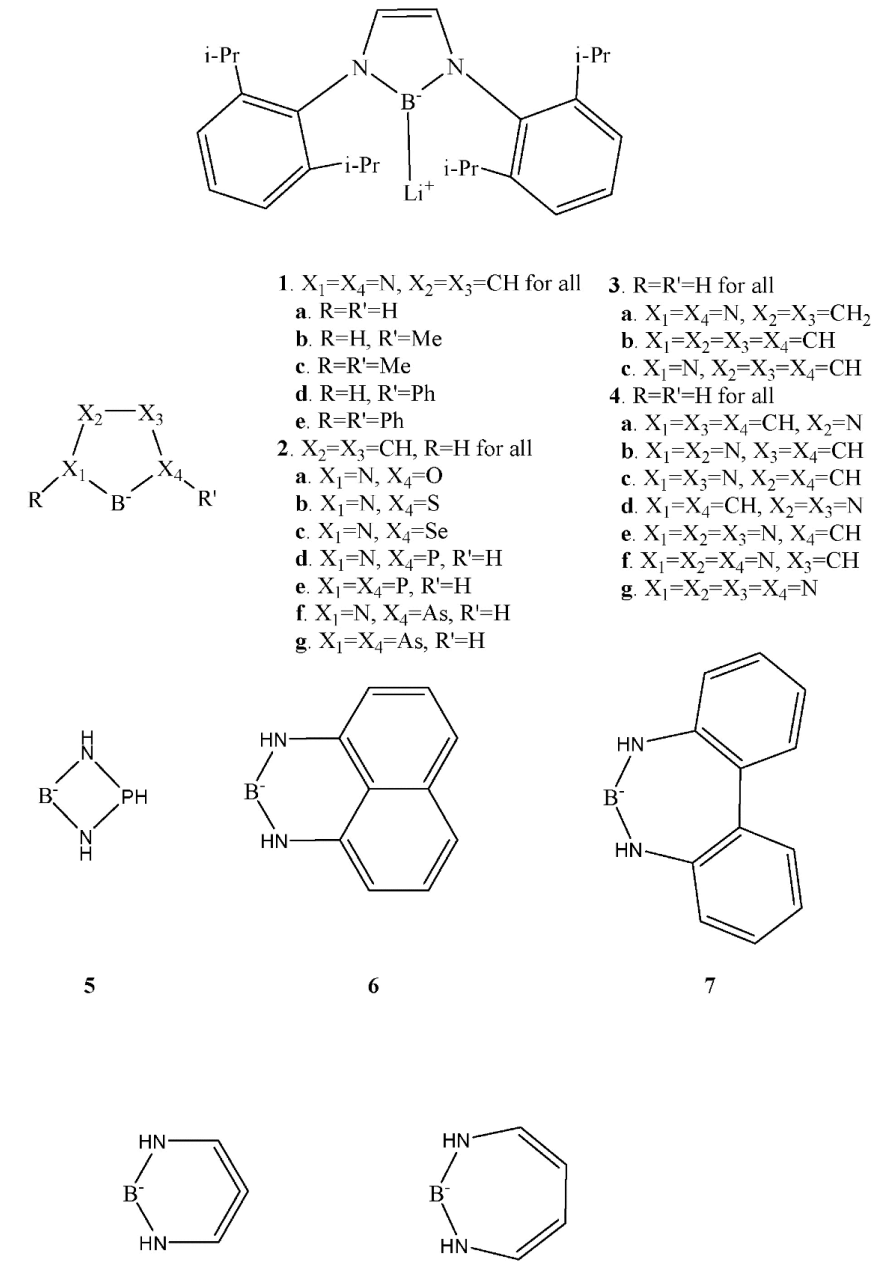

8

9

Scheme 1. The boryllithium reported in ref. 4 and the boryl anions discussed in this study.

\section{The Substituent Effect of R or R' on the Stability of a Boryl Anion}

The transition states of isomerization reactions of 1a-e are depicted in Fig. (1). For a comparison, the previous $\mathrm{HF} / 6-311+\mathrm{G}^{*}$ results are also listed in Fig. (1) [25]. As depicted in Fig. (1), the distance between $\mathrm{N}$ and the migrated $\mathrm{H}$ atom of 1a-TS is calculated to be longer by MPW1K than that calculated by HF; in contrast, the bond distance between $\mathrm{B}$ and the migrated $\mathrm{H}$ atom of 1a-TS is shorter by MPW1K (c.f. HF).

By MPW1K, 1a must overcome a barrier height of 127.5 $\mathrm{kJ} / \mathrm{mol}$, which was calculated to be $198.2 \mathrm{~kJ} / \mathrm{mol}$ based on MP4/6-311+G*//HF/6-311+G*. A more detailed comparison between MPW1K and the previous results can be seen in Table $2[25,26]$. Furthermore, the Miller parameter $\left(\chi^{\ddagger}\right)$ is introduced (see Eq (4)) to investigate the chemical reactivities of 1a-e [27, 28].

$$
\chi^{\neq}(\text {Miller })=\frac{1}{2-\left(\frac{\Delta H_{r}}{\Delta H^{\ddagger}}\right)} \approx \frac{1}{2-\left(\frac{\Delta G_{r}}{\Delta G^{\ddagger}}\right)}
$$


where $\Delta \mathrm{H}_{\mathrm{r}}$ and $\Delta \mathrm{H}^{\ddagger}$ are the reaction and activation enthalpies, respectively. For the Miller parameter, the smaller (larger) $\chi^{\sharp}$ value indicates that the transition state is close to the reactant (product). Since, the reaction free energy $\left(\Delta \mathrm{G}_{\mathrm{r}}\right)$ $=\Delta \mathrm{H}_{\mathrm{r}}-\mathrm{T} \Delta \mathrm{S}_{\mathrm{r}} \approx \Delta \mathrm{H}_{\mathrm{r}}$, and the activation free energy $\left(\Delta \mathrm{G}^{\neq}\right)=$ $\Delta \mathrm{H}^{\neq}-\mathrm{T} \Delta \mathrm{S}^{\neq} \approx \Delta \mathrm{H}^{\neq}$, then the Miller parameter can be calculated by Eq (4). If the shape of the potential energy surface is not altered by solvation, the location of TS on the solvated potential energy surface can also be calculated by Eq. (4). The results are listed in Table 2. Evidently, the barrier of the hydrogen atom transfer reaction does not alter significantly, upon substituting the other $\mathrm{N}-\mathrm{H}$ hydrogen atom in 1a, with a methyl group (Me) in $\mathbf{1 b}$ or a phenyl ring (ph) in 1d. Similar results can be concluded in the methyl group or phenyl ring transfer reaction. Clearly, the migration barrier is in a trend of $\mathrm{Me}>\mathrm{ph}>\mathrm{H}$. This can be rationalized by the fact that hydrogen migration involves a spherical s orbital, whereas, the one with $\mathrm{CH}_{3}$ involves a directed $\mathrm{p} / \mathrm{sp}^{3}$ orbital. Moreover, there may exist a resonance effect between the $\pi$ orbital of a phenyl ring and the empty $\mathrm{p}_{\pi}$ orbital of the boron atom, and/or repulsion between the $\pi$ orbital of a phenyl ring and the filled $\mathrm{p}_{\pi}$ orbital of the nitrogen atom in TS (see Scheme 2), causing the barrier of the phenyl group transfer to be smaller than that of the methyl group transfer.
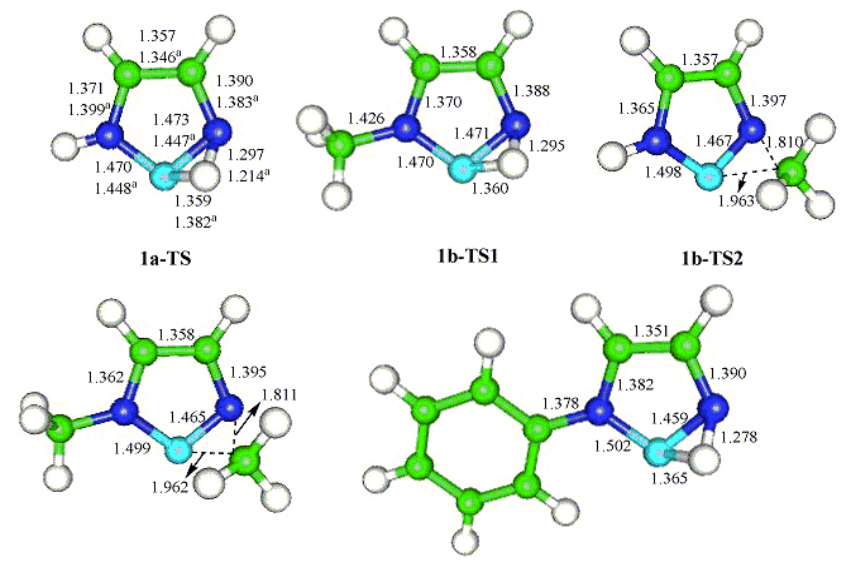

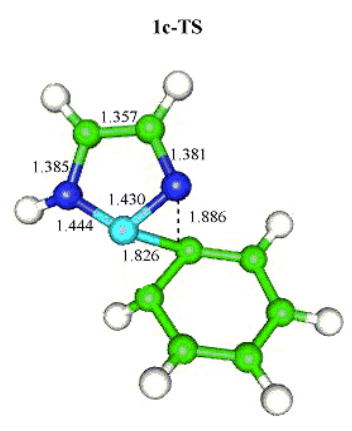

1d-TS2

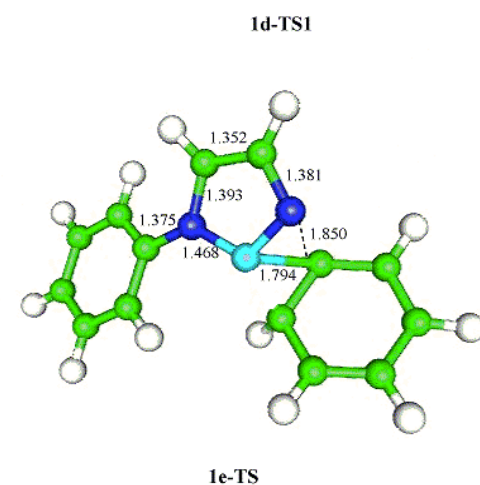

1e-TS
Fig. (1). The critical geometrical parameters of TSs of the isomerization reactions of 1 a-e (bond length in $\AA$, boron in sky blue, nitrogen in navy blue, carbon in green and hydrogen in white). a. The previous $\mathrm{HF} / 6-311+\mathrm{G}^{*}$ results (see ref. [25]).

Recently, it has been reported that the incorporation of boron atoms into the backbone of a polymer can extend its $\pi$ conjugation length through the vacant $\mathrm{p}_{\pi}$ orbital of the boron atom [29]. For a fair comparison, the previous B3LYP results for NHCs are also summarized in Table 2 [30]. The comparison between the boryl anions (1a and 1c) and their carbon analogs (1a-C and 1c-C), shows that both the boryl anions and the NHCs are kinetically stable, with respect to their 1,2-H or Me shifted isomers. It has been reported that there is a lower-barrier dimerization process for a NHC [30]. Such dimerization should not occur for a five-membered boryl anion due to the repulsion between the two negative boron centers.

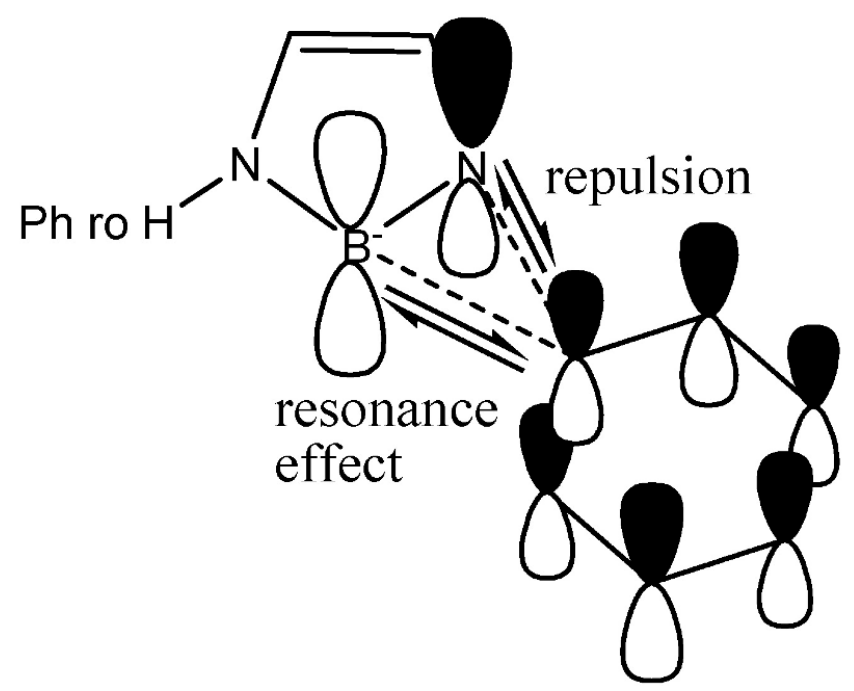

Scheme 2. The illustration of orbital interactions in $1 \mathrm{~d}$ or $1 \mathrm{e}-\mathrm{TS}$.

The boryllithium synthesized by Segawa and coworkers has two bulky groups on the two nitrogen atoms (see the upper part of Scheme 1) [4]. These two bulky groups should induce a large barrier if the boryl anion undergoes such isomerization. On the other hand, these two bulky groups can protect the boron atom from attack by neighboring molecules. Accordingly, 1a-e are kinetically stable with respect to their isomers, i.e. they must overcome large barrier heights, prior to the isomerization. However, their isomers, for which the negative charge is mainly located on nitrogen, are more stable than 1a-e. This should be due to nitrogen being more electronegative than boron. 1a-e, all have early TSs during the isomerization reactions. The result is in agreement with that of Sastry and coworkers, who have reported the $\mathrm{H}$ shifted reactions in many five-membered rings [31]. Accordingly, the Miller parameter, $\chi^{\ddagger}$, is between 0.28 and 0.33 ; thus, the substitution of the hydrogen atom of N-H group by a methyl group or a phenyl ring, does not affect the location of TS on the potential energy surface, along the isomerization reaction. Comparing the results in gas phase and the ones in solvents, it is clear that increasing the solvent polarity leads to the increase in $\Delta \mathrm{G}^{\neq}$and the decrease in $\Delta \mathrm{G}_{\mathrm{r}}$. Therefore, $\chi^{\neq}$increases as the isomerized reaction occurs in polar solvents. The calculated ${ }^{11} \mathrm{~B}$ NMR signals of 1a-e and their isomerized products are summarized in Table 3. Undoubtedly, the isomerized products are less downfield than 1a-e.

\section{The Stabilizing Effects of Other II-Donating Elements}

In 1995, Schleyer and coworkers estimated the energy difference between the singlet and triplet state of a boryl anion to be $3.9 \mathrm{~kJ} / \mathrm{mol}$ in favor of the singlet state [3]. It has 
already been reported that a singlet carbene, which is isoelectronic with a singlet boryl anion, can be stabilized by $\pi$-donating substituents, like halogens and amines [32]. Herein, we investigate further the stabilizing efficiencies of $\pi$-donating substituents on a five-membered boryl anion. We replace one or two nitrogen atoms by other pnicogen ( $\mathrm{P}, \mathrm{As})$, or chalcogen $(\mathrm{O}, \mathrm{S}$ and $\mathrm{Se}$ ) elements, i.e. 2a-g depicted in Scheme 1. The relevant results are summarized in Fig. (2) and Tables $\mathbf{4}$ and $\mathbf{5}$.

Table 2. The Activation Free Energies $\left(\Delta G^{\neq}\right.$in $\left.\mathrm{kJ} / \mathrm{mol}\right)$, Reaction Free Energies $\left(\Delta G_{r}\right.$ in $\left.\mathrm{kJ} / \mathrm{mol}\right)$ and Miller Parameters $\left(\chi^{\ddagger}\right)$ of the Isomerization Reaction of 1a-e

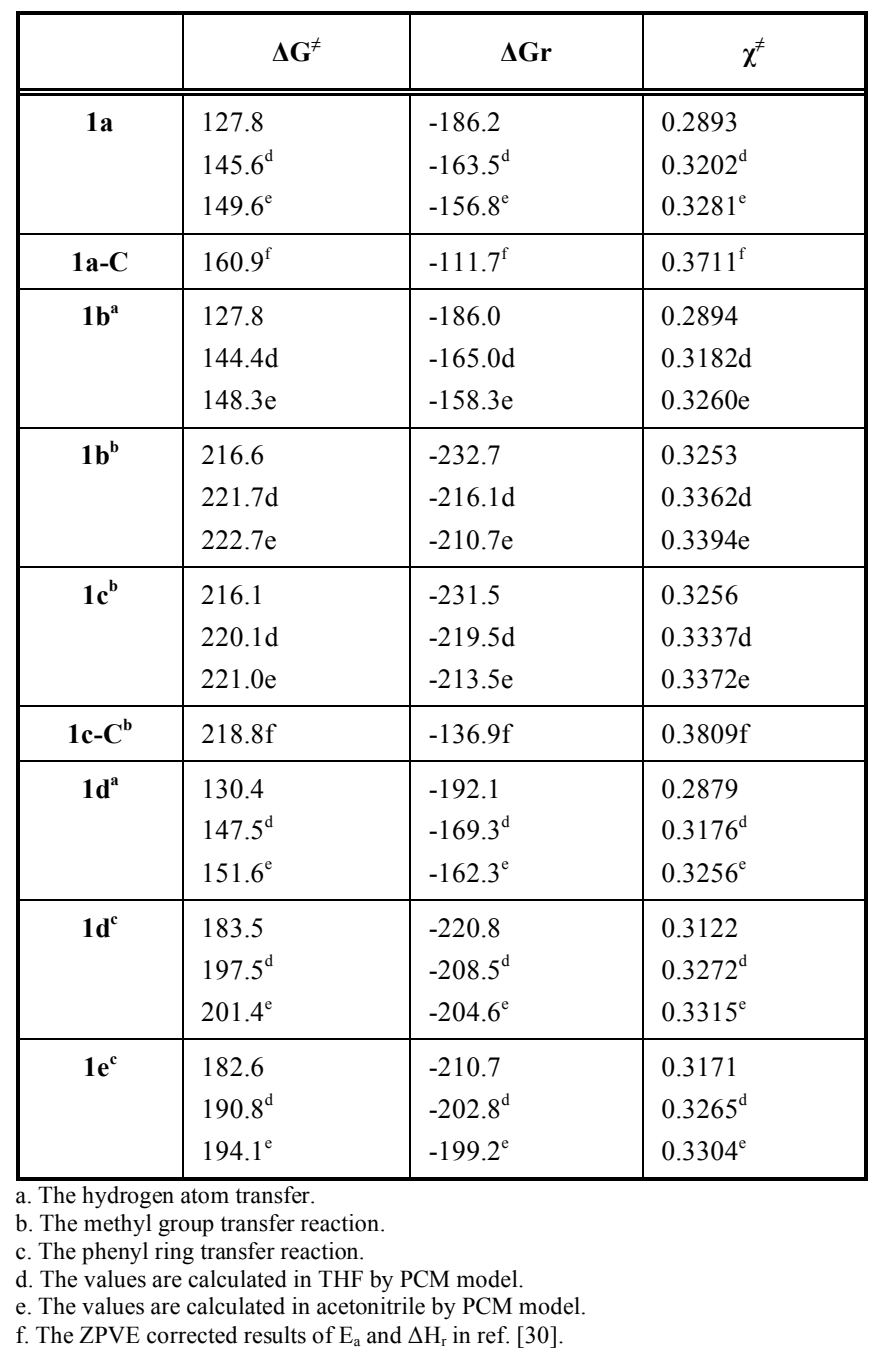

As shown in Table 4, the kinetic stability of a fivemembered boryl anion decreases when the nitrogen atom is replaced by the other group 15 elements. By comparing the data between $1 \mathrm{a}$ and $\mathbf{2 e}$, in the gas phase, the $\Delta \mathrm{G}^{f}$ of hydrogen atom migration of $\mathrm{P}-\mathrm{H}$ group (2e) is calculated to be $43.55 \mathrm{~kJ} / \mathrm{mol}$, which is less than that of $\mathrm{N}-\mathrm{H}$ group (1a) by $84.21 \mathrm{~kJ} / \mathrm{mol}$,. Moreover, $\Delta \mathrm{G}^{\neq}$of the hydrogen atom transfer of As-H group (2g) is calculated to be $31.40 \mathrm{~kJ} / \mathrm{mol}$, which is less than the hydrogen atom migration of N-H group (1a) by $96.36 \mathrm{~kJ} / \mathrm{mol}$. This may be rationalized by the difference in interaction strengths between the empty $\mathrm{p}_{\pi}$ orbital of the boron atom $\left(\mathrm{EP}_{\pi}(\mathrm{B})\right)$ and the filled $\mathrm{p}_{\pi}$ orbital of the group 15 element $\left(\mathrm{FP}_{\pi}\left(\mathrm{X}_{1}\right.\right.$ or $\left.\mathrm{X}_{4}\right), \mathrm{X}_{1}$ or $\mathrm{X}_{4}=\mathrm{N}, \mathrm{P}$ and $\left.\mathrm{As}\right)$. The interaction strengths are in the order $\mathrm{EP}_{\pi}(\mathrm{B})-\mathrm{FP}_{\pi}(\mathrm{N})>\mathrm{EP}_{\pi}(\mathrm{B})$ $\mathrm{FP}_{\pi}(\mathrm{P})>\mathrm{EP}_{\pi}(\mathrm{B})-\mathrm{FP}_{\pi}(\mathrm{As})$ [33]. This can be seen from the calculated dihedral angle $\angle \mathrm{H}-\mathrm{X}_{1}-\mathrm{C}-\mathrm{C}\left(\mathrm{X}_{1}=\mathrm{N}, \mathrm{P}, \mathrm{As}\right)$ in the boryl anions $\mathbf{1 a}, \mathbf{2 e}$ and $\mathbf{2 g}$. The dihedral angles $\angle \mathrm{H}-\mathrm{X}_{1}-\mathrm{C}-\mathrm{C}$ are $180.0^{\circ}, 132.9^{\circ}$ and $121.6^{\circ}$ for $\mathrm{N}, \mathrm{P}$ and As, respectively. The phosphorus and arsenic atoms are pyramidized in $\mathbf{2 e}$ and 2g. The filled p orbital (lone pair) of phosphorus and arsenic is not purely $\pi$ oriented, i.e. they are not perpendicular to the molecular plane. Furthermore, by comparing the results of 1a, $2 \mathbf{e}$ and $\mathbf{2 g}$, the isomerziation barriers are found to have a correlation with respect to the Miller parameters, in which a larger barrier corresponds to a larger Miller parameter, i.e. TS is leaner toward the product. The calculated $\Delta \sigma^{\text {iso }}$ of $\mathbf{2 e}$, $\mathbf{2 g}$ and their H-shifted isomers show similar trends as $\mathbf{1 a}$ and its isomers.

Table 3. The $\Delta \sigma^{\text {iso }}$ on Boron (in ppm) of 1a-e and Their Isomerized Products

\begin{tabular}{|c|c|}
\hline & $\boldsymbol{\Delta \sigma}^{\text {isoa }}$ \\
\hline \hline 1a & -41.40 \\
\hline 1a-Prod1 & -18.00 \\
\hline 1b & -47.11 \\
\hline 1b-Prod1 & -20.94 \\
\hline 1b-Prod2 & -22.65 \\
\hline 1c & -52.45 \\
\hline 1c-Prod1 & -23.97 \\
\hline 1d & -53.41 \\
\hline 1d-Prod1 & -21.65 \\
\hline 1d-Prod2 & -23.49 \\
\hline 1e & -66.87 \\
\hline 1e-Prod1 & -24.94 \\
\hline a. The values are taken as $\sigma^{\text {iso }}$ of the compound- $\sigma^{\text {iso }}$ of $\mathrm{BF}_{3}: \mathrm{OEt}_{2}$. \\
\hline
\end{tabular}

As depicted in Fig. (2), the B-H bond lengths in TS are in the order of 2g-TS $>$ 2e-TS $>$ 1a-TS. This result is in agreement with the Hammond postulate [34]. As the other N-H group is replaced by a group 16 element, according to our calculation, the migration of the hydrogen atom of $\mathrm{N}-\mathrm{H}$ group is not significantly influenced either thermodynamically or kinetically. However, due to the lack of a protecting group, the boron atom in $\mathbf{2 a - c}$ is subject to attack by neighboring molecules. We thus, expect that 2 a-c may be more unstable than 1a. Among these $\pi$-donating elements, nitrogen atom should be the most efficient $\pi$ donor to stabilize a boryl anion.

\section{The Influence of Aromaticity and the Stabilizing Effi- ciency of Nitrogen Atom}

In 1991, Arduengo and coworkers synthesized a stable carbene, which was built by the skeleton, designated as $\mathbf{1 0}$ in Scheme 3 [12]. From then on, a number of theoretical calculations and physical studies had been performed and the results pointed out that cyclic delocalization and/or resonance 
$\left(6 \pi \mathrm{e}^{-}\right)$in the imidazole ring was not a dominant factor to stabilize such carbene [35-39]. Indeed, in 1995, Arduengo and coworkers successfully synthesized the corresponding saturated carbene, the structure of which is represented as $\mathbf{1 1}$ in Scheme 3 [40]. In this study, we are interested in finding whether the aromaticity of the five-membered ring plays a role in the stability of a boryl anion; this can be done by comparing the calculated results of $\mathbf{1 a}$ with those of $\mathbf{3 a}$. As discussed in the above section, nitrogen is the most efficient $\pi$-donating element to stabilize a five-membered boryl anion. The boryl anions $\mathbf{3 b} \mathbf{b}-\mathbf{c}$ are also added to investigate the efficiency of this atom. The relevant results are summarized in Fig. (3) and Tables 6 and 7. As Table 7 shows, the $\mathrm{C}=\mathrm{C}$ double bond of $1 \mathbf{a}$ is saturated to be $\mathbf{3 a}, \Delta \sigma^{\text {iso }}$ of boron changes from-41.40 ppm to-50.72 ppm. The absolute values of $\Delta \sigma^{\text {iso }}$ are calculated to be 198.9, 91.61 and 41.40 for $\mathbf{3 b}, \mathbf{3 c}$ and $\mathbf{1 a}$, respectively.

Table 4. The Activation Free Energies $\left(\Delta G^{\neq}\right.$in $\left.\mathrm{kJ} / \mathrm{mol}\right)$, Reaction Free Energies $\left(\Delta G_{r}\right.$ in $\left.\mathrm{kJ} / \mathrm{mol}\right)$ and Miller Parameters $\left(\chi^{\ddagger}\right)$ of the Isomerization Reactions of $2 \mathrm{a}-\mathrm{g}$

\begin{tabular}{|c|c|c|c|}
\hline & $\Delta \mathbf{G}^{\neq}$ & $\Delta \mathbf{G}_{\mathbf{r}}$ & $\chi^{\ddagger}$ \\
\hline $2 a$ & $\begin{array}{c}123.1^{1} \\
148.3^{\mathrm{c}} \\
154.2^{\mathrm{d}}\end{array}$ & $\begin{array}{c}-202.0 \\
-172.0^{\mathrm{c}} \\
-163.4^{\mathrm{d}}\end{array}$ & $\begin{array}{l}0.2747 \\
0.3165^{\mathrm{c}} \\
0.3268^{\mathrm{d}}\end{array}$ \\
\hline $2 b$ & $\begin{array}{c}133.7 \\
160.1 \mathrm{c} \\
166.0 \mathrm{~d}\end{array}$ & $\begin{array}{c}-201.8 \\
-169.6^{\mathrm{c}} \\
-161.0^{\mathrm{d}}\end{array}$ & $\begin{array}{l}0.2849 \\
0.3269^{\mathrm{c}} \\
0.3367^{\mathrm{d}}\end{array}$ \\
\hline $2 c$ & $\begin{array}{c}135.2 \\
160.9 \mathrm{c} \\
166.5 \mathrm{~d}\end{array}$ & $\begin{array}{c}-198.0 \\
-167.8^{\mathrm{c}} \\
-159.8^{\mathrm{d}}\end{array}$ & $\begin{array}{l}0.2886 \\
0.3286^{\mathrm{c}} \\
0.3379^{\mathrm{d}}\end{array}$ \\
\hline $2 d^{a}$ & $\begin{array}{c}135.1 \\
157.8^{\mathrm{c}} \\
162.5^{\mathrm{d}}\end{array}$ & $\begin{array}{c}-201.3 \\
-171.8^{\mathrm{c}} \\
-164.0^{\mathrm{d}}\end{array}$ & $\begin{array}{l}0.2866 \\
0.3238^{\mathrm{c}} \\
0.3323^{\mathrm{d}}\end{array}$ \\
\hline $2 d^{b}$ & $\begin{array}{l}28.08 \\
26.76^{\mathrm{c}} \\
26.64^{\mathrm{d}}\end{array}$ & $\begin{array}{c}-265.6 \\
-255.4^{\mathrm{c}} \\
-252.1^{\mathrm{d}}\end{array}$ & $\begin{array}{l}0.0873 \\
0.0866^{\mathrm{c}} \\
0.0872^{\mathrm{d}}\end{array}$ \\
\hline $2 e^{b}$ & $\begin{array}{l}43.55 \\
43.55^{\mathrm{c}} \\
43.55^{\mathrm{d}}\end{array}$ & $\begin{array}{c}-254.8 \\
-238.0^{\mathrm{c}} \\
-233.1^{\mathrm{d}}\end{array}$ & $\begin{array}{l}0.1274 \\
0.1340^{\mathrm{c}} \\
0.1360^{\mathrm{d}}\end{array}$ \\
\hline $2 f^{a}$ & $\begin{array}{c}136.3 \\
159.6^{\mathrm{c}} \\
164.7 \mathrm{~d}\end{array}$ & $\begin{array}{l}-198.5 \\
-170.5^{\mathrm{c}} \\
-162.9^{\mathrm{d}}\end{array}$ & $\begin{array}{c}02893 \\
0.3260^{\mathrm{c}} \\
0.3345^{\mathrm{d}}\end{array}$ \\
\hline $2 f^{b}$ & $\begin{array}{c}24.59 \\
20.40 \mathrm{c} \\
19.78 \mathrm{~d}\end{array}$ & $\begin{array}{c}-274.4^{\mathrm{c}} \\
-266.4^{\mathrm{c}} \\
-263.7^{\mathrm{d}}\end{array}$ & $\begin{array}{l}0.0760 \\
0.0664^{\mathrm{c}} \\
0.0652^{\mathrm{d}}\end{array}$ \\
\hline $2 \mathrm{~g}^{\mathrm{b}}$ & $\begin{array}{c}31.40 \\
28.08 \mathrm{c} \\
27.50 \mathrm{~d}\end{array}$ & $\begin{array}{l}-269.7 \\
-257.5^{c} \\
-253.8^{d}\end{array}$ & $\begin{array}{c}0.0944 \\
0.0895^{\mathrm{c}} \\
0.0891^{\mathrm{d}}\end{array}$ \\
\hline
\end{tabular}

a. The hydrogen atom transfer of the $\mathrm{N}-\mathrm{H}$ group.

b. The hydrogen atom transfer of the P-H or As-H group.

c. The values are calculated in THF by PCM model.

d. The values are calculated in acetonitrile by PCM model.

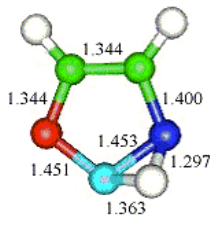

2a-TS

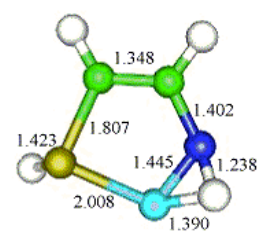

2d-TS1

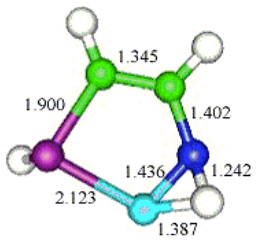

2f-TS1

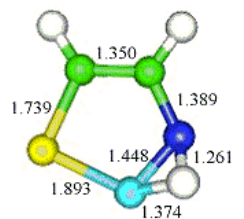

2b-TS

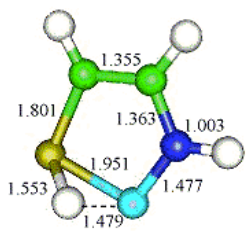

2d-TS2

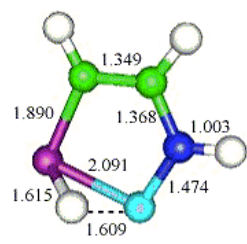

2f-TS2

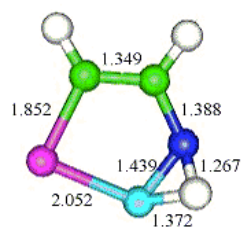

2c-TS

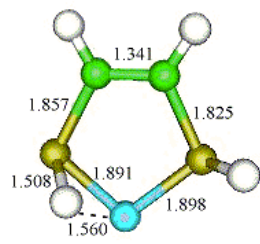

2e-TS

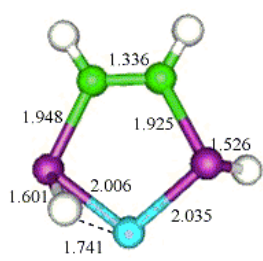

2g-TS
Fig. (2). The critical geometrical parameters of TSs of the isomerization reactions of $2 \mathrm{a}-\mathrm{g}$ (bond length in $\AA$, boron in sky blue, oxygen in red, sulfur in yellow, selenium in pink, nitrogen in navy blue, phosphorous in gold, arsenic in purple, carbon in green and hydrogen in white).

Table 5. The $\Delta \sigma^{\text {iso }}$ on Boron (in ppm) of 2a-g and Their Isomerized Products

\begin{tabular}{|c|c|}
\hline & $\boldsymbol{\Delta \sigma}^{\text {isoa }}$ \\
\hline \hline 2a & -48.57 \\
\hline 2a-Prod1 & -25.19 \\
\hline 2b & -63.21 \\
\hline 2b-Prod1 & -29.91 \\
\hline 2c & -69.95 \\
\hline 2c-Prod1 & -31.66 \\
\hline $\mathbf{2 d}$ & -103.0 \\
\hline 2d-Prod1 & -43.25 \\
\hline 2d-Prod2 & -34.75 \\
\hline 2e & -185.6 \\
\hline 2e-Prod1 & -61.79 \\
\hline 2f & -107.5 \\
\hline 2f-Prod1 & -43.42 \\
\hline 2f-Prod2 & -38.50 \\
\hline 2g & -244.3 \\
\hline 2g-Prod1 & -70.93 \\
\hline
\end{tabular}

a. The values are taken as $\sigma$ iso of the compound-бiso of $\mathrm{BF}_{3}: \mathrm{OEt}_{2}$. 
As shown in Table 6, the boryl anion 3a has a similar isomerization barrier, as 1a. Furthermore, the Miller parameter of $\mathbf{3 a}$ is calculated to be larger than that of $\mathbf{1 a}$, indicating that TS of 3a is leaner toward the isomer. The B3LYP results, regarding the 1,2-H shifted reaction of $\mathbf{1 1}$ in Scheme $\mathbf{3}$ are also listed in Table 6 [30]. As listed in Table 6, the carbon counterpart of $\mathbf{3 a}$, which is designated as $\mathbf{3 a - C}$, has a similar barrier as 1a-C. Considering the exothermicities the saturated boryl anion (3a) and NHC (3a-C) have lower exothermicities than that of the unsaturated ones. In fact, the bulky-group substituted 3a, has been synthesized successfully and shows little influence on its donor ability with group 11 metals [6]. Moreover, TS of $\mathbf{3 a}$ has a longer Ntransferred $\mathrm{H}$ but shorter B-transferred $\mathrm{H}$ bond than that of 1a (see Fig. 3). Owing to the lack of a $\pi$-donating capacity, carbon cannot stabilize the boryl anion. According to our calculation, the hydrogen atom transfer of $\mathrm{CH}_{2}$ group has a lower barrier than that of the NH group by $81.31 \mathrm{~kJ} / \mathrm{mol}$. The bond length of the B-H bond in $\mathbf{3 b}$-TS is longer than the bond length in 1a-TS, the result of which is in agreement with the fact that $\mathbf{3 b}$ has a smaller Miller parameter. According to the similar $\mathrm{H}$-shifted barrier of $\mathrm{N}-\mathrm{H}$ group for both 3c and 1a, the existence of one nitrogen atom (in 3c) may be sufficient to stabilize the five-membered boryl anion kinetically.

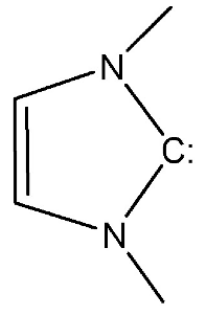

$6 \pi \mathrm{e}^{-}$

10

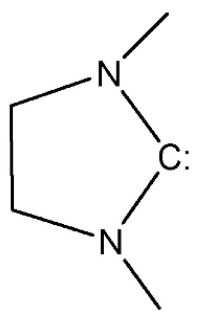

$4 \pi \mathrm{e}^{-}$

11
Scheme 3. The skeletons of Arduengo carbenes.

\section{The Influences of the Numbers and Positions of Nitro- gen on the Stability of a Five-Membered Boryl Anion}

Nitrogen is considered to play dual roles. On one hand, having one filled lone pair, it can behave as a $\pi$-donor. On the other hand, it also acts as an $\sigma$-acceptor owing to its large electronegativity. In this section, we thus investigate how the numbers and positions of nitrogen on the five-membered ring affect the stability of a five-membered boryl anion. The relevant results are summarized in Fig. (4) and Tables $\mathbf{8}$ and 9. Notably, 4a has two kinds of $\mathrm{CH}_{2}$ groups, which can undergo the $\mathrm{H}$ atom migration. One is close to nitrogen and the other is close to the $\mathrm{CH}$ group. Similar condition can be seen in $\mathbf{4 f}$, for which one $\mathrm{NH}$ group is close to the $\mathrm{CH}$ group and the other is close to nitrogen. As listed in Table 4, 4a-Prod2, which is the product of the second isomerization reaction of 4a, is more stable than $\mathbf{4 a - P r o d} 1$ by $32.79 \mathrm{~kJ} / \mathrm{mol}$, despite the two reactions have similar barriers. This can be rationalized by the repulsion between the filled $\mathrm{p}_{\pi}$ orbitals of nitrogen and carbon anion (see Scheme 4). Similar explanation
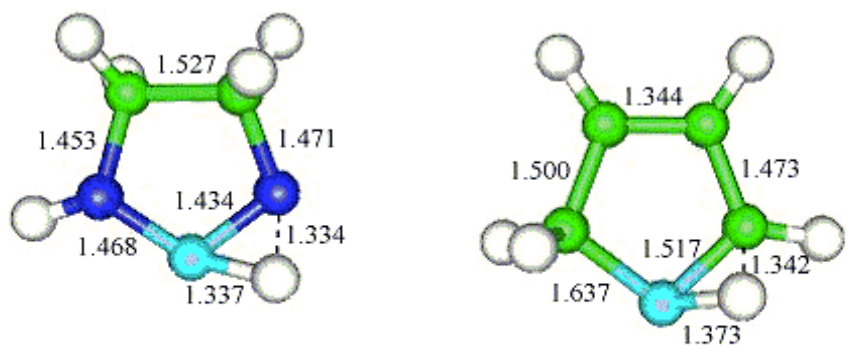

3a-TS
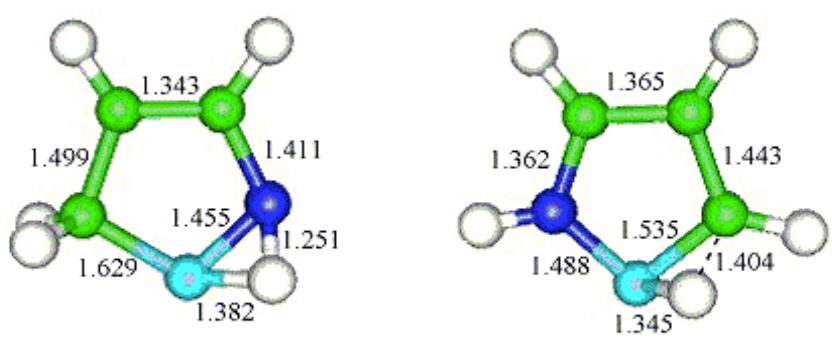

3c-TS1

3c-TS2

Fig. (3). The critical geometrical parameters of TSs of the isomerization reactions of 3a-c (bond length in $\AA$, boron in sky blue, nitrogen in navy blue, carbon in green and hydrogen in white).

Table 6. The Activation Free Energies $\left(\Delta G^{\neq}\right.$in $\left.\mathrm{kJ} / \mathrm{mol}\right)$, Reaction Free Energies $\left(\Delta G_{r}\right.$ in $\left.\mathrm{kJ} / \mathrm{mol}\right)$ and Miller Parameters $\left(\chi^{\ddagger}\right)$ of the Isomerization Reactions of 3a-c

\begin{tabular}{|c|c|c|c|}
\hline & $\Delta \mathbf{G}^{\neq}$ & $\Delta \mathbf{G}_{\mathrm{r}}$ & $\chi^{\ddagger}$ \\
\hline $3 a^{a}$ & $\begin{array}{c}133.5 \\
153.7^{\mathrm{c}} \\
158.8^{\mathrm{d}}\end{array}$ & $\begin{array}{l}-153.9 \\
-136.2^{\mathrm{c}} \\
-130.5^{\mathrm{d}}\end{array}$ & $\begin{array}{l}0.3171 \\
0.3465^{\mathrm{c}} \\
0.3544^{\mathrm{d}}\end{array}$ \\
\hline $3 \mathrm{a}-\mathrm{C}^{\mathrm{a}}$ & $162.5^{\mathrm{e}}$ & $-88.62^{\mathrm{e}}$ & $0.3929^{\circ}$ \\
\hline $3 b^{b}$ & $\begin{array}{c}46.45 \\
46.70^{\mathrm{c}} \\
47.01^{\mathrm{d}}\end{array}$ & $\begin{array}{l}-232.2^{\mathrm{c}} \\
-208.3^{\mathrm{c}} \\
-200.2^{\mathrm{d}}\end{array}$ & $\begin{array}{l}0.1429 \\
0.1548^{\mathrm{c}} \\
0.1598^{\mathrm{d}}\end{array}$ \\
\hline $3 c^{a}$ & $\begin{array}{l}129.1 \\
150.2^{\mathrm{c}} \\
154.9^{\mathrm{d}}\end{array}$ & $\begin{array}{l}-196.7 \\
-172.7^{\mathrm{c}} \\
-165.4^{\mathrm{d}}\end{array}$ & $\begin{array}{l}0.2838 \\
0.3175^{\mathrm{c}} \\
0.3260^{\mathrm{d}}\end{array}$ \\
\hline $3 c^{b}$ & $\begin{array}{c}51.85 \\
50.95^{\mathrm{c}} \\
50.81^{\mathrm{d}}\end{array}$ & $\begin{array}{l}-214.4 \\
-193.7^{\mathrm{c}} \\
-187.0^{\mathrm{d}}\end{array}$ & $\begin{array}{l}0.1630 \\
0.1724^{\mathrm{c}} \\
0.1761^{\mathrm{d}}\end{array}$ \\
\hline
\end{tabular}

a. The hydrogen atom transfer of the $\mathrm{N}-\mathrm{H}$ group.

b. The hydrogen atom transfer of the $\mathrm{CH}_{2}$ group.

c. The values are calculated in THF by PCM model.

d. The values are calculated in acetonitrile by PCM model.

e. The ZPVE corrected results of $E_{a}$ and $\Delta H_{r}$ in ref. [30].

can be applied to the difference in energetics between $\mathbf{4 f}$ Prod1 and 4f-Prod2. Furthermore, as shown in Table 8, all $\mathrm{H}$-shifted reactions of the $\mathrm{CH}_{2}$ group, have smaller Miller parameters and barriers than those of the $\mathrm{NH}$ group. This is again consistent with the Hammond postulate [34]. When 
comparing with 1a, the bond length of $\mathrm{X}_{2}-\mathrm{X}_{3}$ in Scheme 1 decreases from $1.351 \AA$ to $1.255 \AA$, as the number of nitrogen atom increases from zero to two. This result is qualitatively in agreement with the van-der Waals radius of carbon and nitrogen. Thus, nitrogen atom seems only to behave as a $\pi$-donor in the five-membered boryl anion. The 1,2-H shifted barrier $E_{a}$ increases as the number of nitrogen atom in the five member ring increases.

Table 7. The $\Delta \sigma^{\text {iso }}$ on Boron (in ppm) of 3a-c and Their Isomerized Products

\begin{tabular}{|c|c|}
\hline & $\Delta \boldsymbol{\sigma}^{\text {isoa }}$ \\
\hline \hline 3a & -50.72 \\
\hline 3a-Prod1 & -26.26 \\
\hline 3b & -198.9 \\
\hline 3b-Prod1 & -34.71 \\
\hline 3c & -91.61 \\
\hline 3c-Prod1 & -41.59 \\
\hline 3c-Prod2 & -13.17 \\
\hline
\end{tabular}

a. The values are taken as $\sigma^{\text {iso }}$ of the compound $-\sigma^{\text {iso }}$ of $\mathrm{BF}_{3}: \mathrm{OEt}_{2}$.

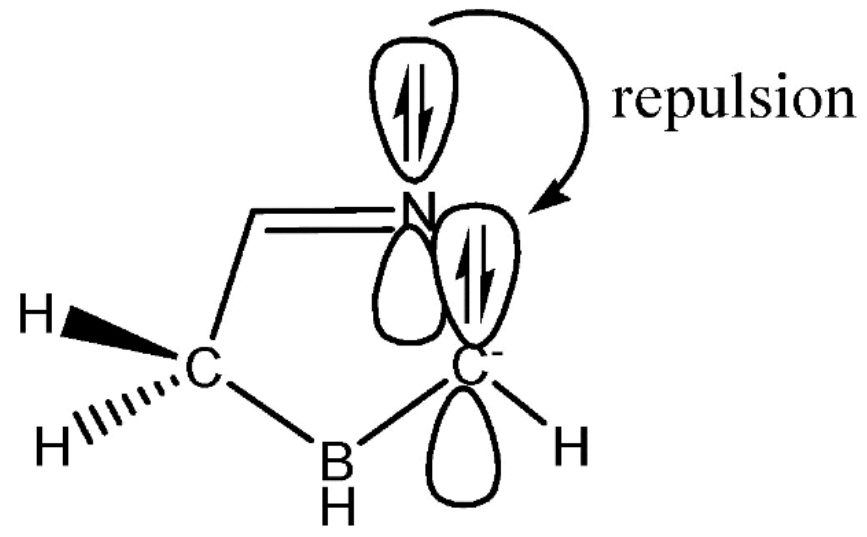

Scheme 4. The repulsive interaction in 4a-Prod1.

\section{The Comparison of Four-, Five-, Six-and Seven- Membered Boryl Anion}

Due to the ability to transform an electron-deficient carbene into the realm of isolable compounds [12], they have already acted as powerful tools for synthetic chemists. So far, only five membered NHCs (see 10 and 11 in Scheme 3) have been widely applied as catalysts [13]. Therefore, it is interesting to design new stable cyclic diamino carbenes, possessing different scaffolds and electronic structures. Very recently, Grubbs and coworkers synthesized a stable fourmembered NHC 12 (in Scheme 5), and found that the ring was not strictly planar [15]. The six-(13 in Scheme 5) and seven-membered (14 in scheme 5) NHCs have been synthesized by Präsang and Scarborough, respectively [16,17].

In 2006 , the synthesized boryllithium was built by a fivemembered ring scaffold. In this study, the corresponding
Table 8. The Activation Free Energies $\left(\Delta G^{f}\right.$ in $\left.\mathrm{kJ} / \mathrm{mol}\right)$, Reaction Free Energies $\left(\Delta G_{r}\right.$ in $\left.\mathrm{kJ} / \mathrm{mol}\right)$ and Miller Parameters $\left(\chi^{*}\right)$ of the Isomerization Reactions of $4 \mathrm{a}-\mathrm{g}$

\begin{tabular}{|c|c|c|c|}
\hline & $\Delta \mathbf{G}^{\neq}$ & $\Delta \mathbf{G}_{\mathbf{r}}$ & $\chi^{*}$ \\
\hline 4a $(\text { Path } 1)^{b}$ & $\begin{array}{c}45.75 \\
46.93^{c} \\
47.49^{d}\end{array}$ & $\begin{array}{c}-220.2 \\
-202.0^{\mathrm{c}} \\
-195.9^{\mathrm{d}}\end{array}$ & $\begin{array}{c}0.1468 \\
0.1586^{\mathrm{c}} \\
0.1633^{\mathrm{d}}\end{array}$ \\
\hline 4a $($ Path 2) & $\begin{array}{c}42.63 \\
47.81^{\mathrm{c}} \\
49.40^{\mathrm{d}}\end{array}$ & $\begin{array}{l}-253.0 \\
-234.6^{\mathrm{c}} \\
-228.2^{\mathrm{d}}\end{array}$ & $\begin{array}{l}0.1260 \\
0.1448^{\mathrm{c}} \\
0.1511^{\mathrm{d}}\end{array}$ \\
\hline $4 b^{a}$ & $\begin{array}{c}144.5 \\
154.8^{\mathrm{c}} \\
156.8^{\mathrm{d}}\end{array}$ & $\begin{array}{c}-160.3 \\
-155.0^{\mathrm{c}} \\
-152.7^{\mathrm{d}}\end{array}$ & $\begin{array}{l}0.3216 \\
0.3332^{\mathrm{c}} \\
0.3363^{\mathrm{d}}\end{array}$ \\
\hline $4 b^{b}$ & $\begin{array}{c}48.56 \\
54.50^{\mathrm{c}} \\
56.50^{\mathrm{d}}\end{array}$ & $\begin{array}{l}-243.6^{c} \\
-228.1^{\mathrm{c}} \\
-222.2^{\mathrm{d}}\end{array}$ & $\begin{array}{c}0.1425 \\
0.1617^{\mathrm{c}} \\
0.1685^{\mathrm{d}}\end{array}$ \\
\hline $4 c^{a}$ & $\begin{array}{c}135.6 \\
162.4^{\mathrm{c}} \\
168.7^{\mathrm{d}}\end{array}$ & $\begin{array}{c}-205.1 \\
-182.9^{\mathrm{c}} \\
-176.0^{\mathrm{d}}\end{array}$ & $\begin{array}{c}0.2847 \\
0.3199^{\mathrm{c}} \\
0.3286^{\mathrm{d}}\end{array}$ \\
\hline $4 c^{b}$ & $\begin{array}{l}51.45 \\
50.45^{\mathrm{c}} \\
50.76^{\mathrm{d}}\end{array}$ & $\begin{array}{c}-203.9 \\
-191.3^{\mathrm{c}} \\
-186.7^{\mathrm{d}}\end{array}$ & $\begin{array}{c}0.1677 \\
0.1726^{\mathrm{c}} \\
0.1761^{\mathrm{d}}\end{array}$ \\
\hline $4 d^{b}$ & $\begin{array}{c}39.62 \\
44.35^{\mathrm{c}} \\
46.11^{\mathrm{d}}\end{array}$ & $\begin{array}{c}-246.9^{-2} \\
-237.5^{\mathrm{c}} \\
-233.3^{\mathrm{d}}\end{array}$ & $\begin{array}{c}0.1215 \\
0.1360^{\mathrm{c}} \\
0.1416^{\mathrm{d}}\end{array}$ \\
\hline 4ea & $\begin{array}{c}146.1^{1} \\
162.3^{\mathrm{c}} \\
165.7^{\mathrm{d}}\end{array}$ & $\begin{array}{l}-172.0 \\
-167.6^{\mathrm{c}} \\
-165.4^{\mathrm{d}}\end{array}$ & $\begin{array}{c}0.3147 \\
0.3298^{\mathrm{c}} \\
0.3335^{\mathrm{d}}\end{array}$ \\
\hline $4 \mathrm{eb}$ & $\begin{array}{c}42.95 \\
43.79^{\mathrm{c}} \\
44.70^{\mathrm{d}}\end{array}$ & $\begin{array}{l}-243.8^{-2} \\
-242.2^{\mathrm{c}} \\
-240.0^{\mathrm{d}}\end{array}$ & $\begin{array}{c}0.1303 \\
0.1328^{\mathrm{c}} \\
0.1357^{\mathrm{d}}\end{array}$ \\
\hline 4f $(\text { Path 1) })^{a}$ & $\begin{array}{c}147.3 \\
155.8^{\mathrm{c}} \\
157.4^{\mathrm{d}}\end{array}$ & $\begin{array}{c}-147.3 \\
-145.7^{\mathrm{c}} \\
-144.6^{\mathrm{d}}\end{array}$ & $\begin{array}{c}0.3334 \\
0.3406^{\mathrm{c}} \\
0.3426^{\mathrm{d}}\end{array}$ \\
\hline $4 f(\text { Path 2) })^{a}$ & $\begin{array}{c}135.4 \\
162.9^{\mathrm{c}} \\
169.3^{\mathrm{d}}\end{array}$ & $\begin{array}{l}-201.6 \\
-178.8^{\mathrm{c}} \\
-171.6^{\mathrm{d}}\end{array}$ & $\begin{array}{c}0.2866 \\
0.3229^{c} \\
0.3318^{d}\end{array}$ \\
\hline $4 g^{a}$ & $\begin{array}{l}221.3 \\
168.9^{\mathrm{c}} \\
172.3^{\mathrm{d}}\end{array}$ & $\begin{array}{c}-169.5 \\
-166.3^{c} \\
-164.4^{d}\end{array}$ & $\begin{array}{c}0.3616 \\
0.3351^{\mathrm{c}} \\
0.3385^{\mathrm{d}}\end{array}$ \\
\hline
\end{tabular}

a. The hydrogen atom transfer of the $\mathrm{N}-\mathrm{H}$ group.

b. The hydrogen atom transfer of the $\mathrm{CH}_{2}$ group.

c. The values are calculated in THF by PCM model.

d. The values are calculated in acetonitrile by PCM model.

four-, six-and seven-membered boryl anions $(5,6,7,8$ and 9 in Scheme 1) are compared with 1a. In the first place, the bond lengths of B-N and bond angle, $\angle N-B-N$, of each species are collected in Fig. (5). Previous results of 1a are also depicted in Fig. (5), for a comparison [25, 26, 41]. The geometry of $1 \mathrm{a}$ derived from MPW1K, such as the B-N bond distances and N-B-N bond angle, is similar to that of the 


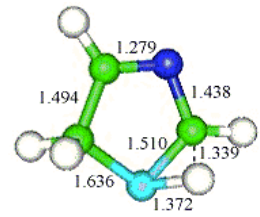

4a-TS1

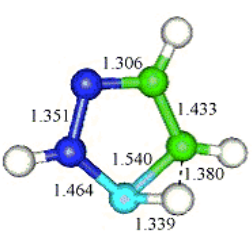

$4 b-T S 2$

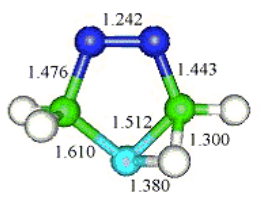

$4 d-T S$

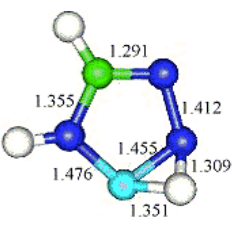

4f-TS1

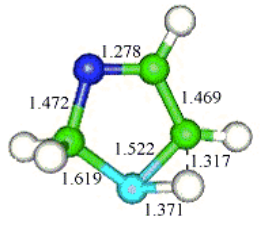

4a-TS2

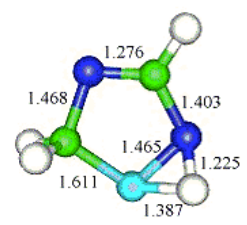

$4 \mathrm{c}-\mathrm{TS} 1$

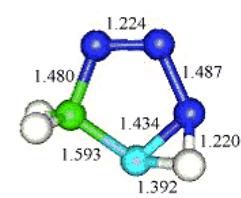

4e-TS1

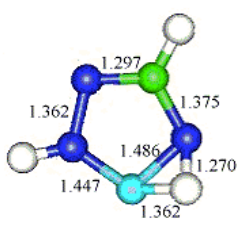

4f-TS2

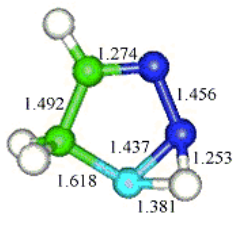

4b-TS1

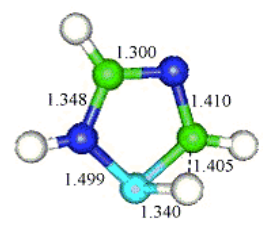

$4 \mathrm{c}-\mathrm{TS} 2$

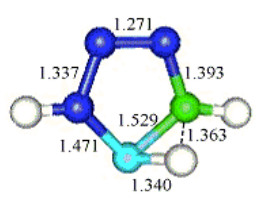

4e-TS2

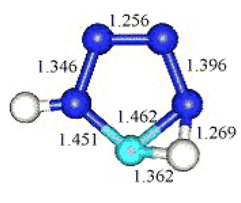

4g-TS
Fig. (4). The critical geometrical parameters of TSs of the isomerization reactions of $4 \mathrm{a}-\mathrm{f}$ (bond length in $\AA$, boron in sky blue, nitrogen in navy blue, carbon in green and hydrogen in white).

previous reports $[25,26,41]$. As depicted in Fig. (5), 5 has the longest B-N bonds among these boryl anions $(\mathbf{1 a}, \mathbf{5}, \mathbf{6}, \mathbf{7}$, 8 and 9). This may imply that 5 has the weakest $\mathrm{EP}_{\pi}(\mathrm{B})-$ $\mathrm{FP}_{\pi}(\mathrm{N})$ interactions among these boryl anions. The sum of the bond angles around the nitrogen atom is $360^{\circ}$, if the ring is in a planar conformation. Otherwise, a value deviated from $360.0^{\circ}$ is obtained. As a result of calculation, they are $360.0^{\circ}, 340.6^{\circ}, 360^{\circ}, 349.2^{\circ}, 360.0^{\circ}$ and $356.0^{\circ}$ for $1 \mathrm{a}, \mathbf{5 ,}, \mathbf{6}, 7$, 8 and $\mathbf{9}$, respectively. Accordingly, 1a (five-membered), 6 and $\mathbf{8}$ (six-membered) are planar, while, $\mathbf{5}$ (four-membered), 7 and 9 (seven-membered) are in twisted forms, the results of which are in agreement with the previous reports regarding 12, 13 and 14, depicted in Scheme 5 [15-17, 42, 43]. The sum of the bond angles around nitrogen was $348.2^{\circ}$ for the four-membered NHC 12 [15]. Rzepa and coworkers used DFT computational methods to analyze a series of $8 \pi$ electron heterocycles, including seven-membered NHC [42, 43]. Such antiaromatic heterocyclic rings were found to gain Möbius aromatic stabilization and release of the ring strain intrinsic to seven-membered rings by undergoing torsional twist. Presumably due to the ring strain, the four-membered boryl anion (5) and NHC (12) are not planar [15]. Accordingly, it can be said that the additional aromatic rings of $\mathbf{6}$ and 7 do not change the geometries of the boryl anions as compared with 8 and $\mathbf{9}$. The calculated free energies of activation, the reaction free energies, and the Miller parame ters of the H-shifted reactions of $\mathbf{5 , 6}, \mathbf{7}, \mathbf{8}$ and $\mathbf{9}$ are summarized in Table 10. The geometries of TSs of the $\mathrm{H}$ atom migration reactions of 5, 6, 7, 8 and 9 are depicted in Fig. (6). As shown in Table 10, $\mathbf{6}$ is kinetically most stable due to the fact that it has the largest isomerization barrier. Due to the similar activation free energy, $\mathbf{5}$ is nearly stable to $\mathbf{1 a}$ kinetically although it has a larger ring strain. Although the additional aromatic rings of $\mathbf{6}$ and $\mathbf{7}$ do not change their geometries, they induce larger activation free energies of the $\mathrm{H}$ shifted reactions, if making a comparison between $\mathbf{6}$ and $\mathbf{8}$, or between 7 and 9. Finally, the calculated $\Delta \sigma^{\text {iso }}$ s of 5-9 are summarized in Table 11. As given in Table 11, the ring size can alter the calculated $\Delta \sigma^{\text {iso }}$ of the boryl anion, this may indicate the negatively charged character of boron of the boryl anion is influenced by the ring size.

Table 9. The $\Delta \sigma^{\text {iso }}$ on Boron (in ppm) of 4a-g and Their Isomerized Products

\begin{tabular}{|c|c|}
\hline & $\Delta \sigma^{\text {isoa }}$ \\
\hline $4 a$ & -188.8 \\
\hline 4a-Prod1 & -26.65 \\
\hline 4a-Prod2 & -40.53 \\
\hline $4 b$ & -75.20 \\
\hline 4b-Prod1 & -34.26 \\
\hline 4b-Prod2 & -14.24 \\
\hline $4 c$ & -92.50 \\
\hline 4c-Prod1 & -46.48 \\
\hline 4c-Prod 2 & -10.80 \\
\hline $4 d$ & -171.3 \\
\hline 4d-Prod1 & -34.89 \\
\hline $4 e$ & -74.09 \\
\hline 4e-Prod1 & -39.76 \\
\hline 4e-Prod2 & -11.21 \\
\hline $4 \mathrm{f}$ & -33.87 \\
\hline 4f-Prod1 & -18.22 \\
\hline 4f-Prod2 & -18.43 \\
\hline $4 \mathrm{~g}$ & -26.15 \\
\hline 4g-Prod1 & -17.61 \\
\hline
\end{tabular}

a. The values are taken as $\sigma^{\text {iso }}$ of the compound- $\sigma^{\text {iso }}$ of $\mathrm{BF}_{3}: \mathrm{OEt}_{2}$.<smiles>CN1CN(C)I1C</smiles><smiles>CN1CN(C)c2cccc3cccc1c23</smiles>

12 13

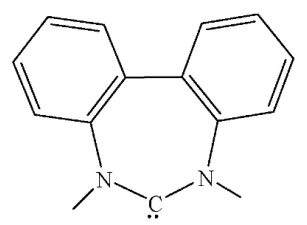

14

Scheme 5. The scaffolds of four-, six-and seven-membered Nheterocyclic carbene

In 2006, Dixon and coworkers found that NHCs could be good candidates, to act as hydrogen storage materials, by a 

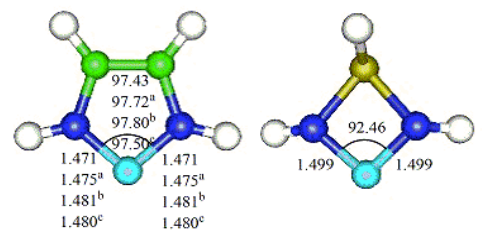

1a
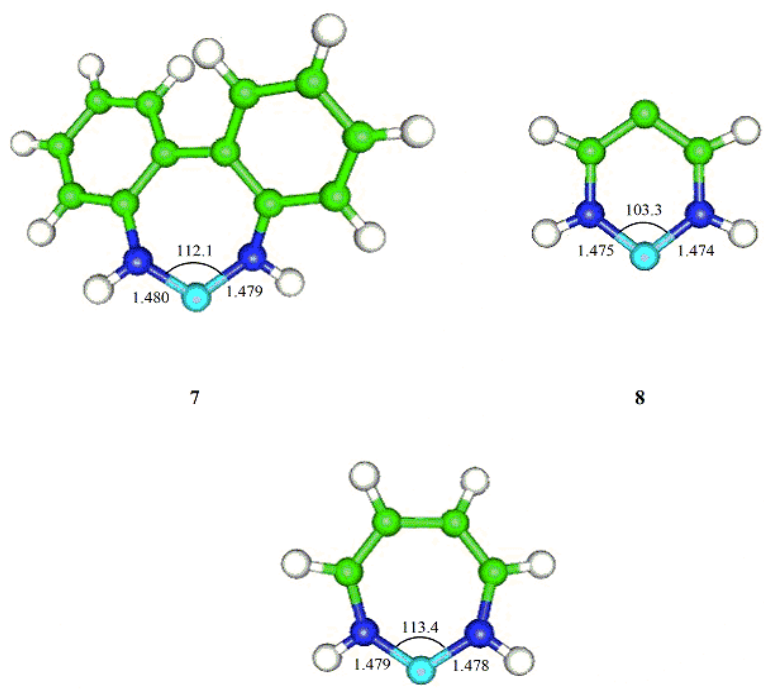

Fig. (5). The critical geometry parameters of 1a, 5, 6, 7, 8 and 9 (bond lengths in $\AA$, bond angles in ${ }^{\circ}$, boron in sky blue, nitrogen in navy blue, phosphorus in gold, carbon in green and hydrogen in white). a. The value is calculated by $\mathrm{HF} / 6-311+\mathrm{G}^{*}$, see ref. [25]. b. The value is calculated by DFT/6-31++G**, see ref. [26]. c. The value is calculated by MP2/6-311++G**, see ref. [41].

Table 10. The Activation Free Energies $\left(\Delta G^{\neq}\right.$in $\left.\mathrm{kJ} / \mathrm{mol}\right)$, Reaction Free Energies $\left(\Delta G_{r}\right.$ in $\left.\mathrm{kJ} / \mathrm{mol}\right)$ and Miller Parameters $\left(\chi^{\ddagger}\right)$ of the Isomerization Reactions of 5, 6, 7,8 and 9

\begin{tabular}{|c|c|c|c|}
\hline & $\boldsymbol{\Delta} \mathbf{G}^{\ddagger}$ & $\boldsymbol{\Delta} \mathbf{G}_{\mathbf{r}}$ & $\boldsymbol{\chi}^{\ddagger}$ \\
\hline \hline $\mathbf{5}$ & 128.1 & -175.6 & 0.2967 \\
& $148.2^{\mathrm{a}}$ & $-161.7^{\mathrm{a}}$ & $0.3236^{\mathrm{a}}$ \\
& $153.0^{\mathrm{b}}$ & $-157.1^{\mathrm{b}}$ & $0.3303^{\mathrm{b}}$ \\
\hline $\mathbf{6}$ & 148.0 & -210.4 & 0.2923 \\
& $169.3^{\mathrm{a}}$ & $-182.8^{\mathrm{a}}$ & $0.3247^{\mathrm{a}}$ \\
& $172.9^{\mathrm{b}}$ & $-177.3^{\mathrm{b}}$ & $0.3306^{\mathrm{b}}$ \\
\hline $\mathbf{7}$ & 144.3 & -207.2 & 0.2910 \\
& $164.7^{\mathrm{a}}$ & $-179.3^{\mathrm{a}}$ & $0.3238^{\mathrm{a}}$ \\
& $168.9^{\mathrm{b}}$ & $-173.3^{\mathrm{b}}$ & $0.3305^{\mathrm{b}}$ \\
\hline $\mathbf{8}$ & 134.3 & -215.7 & 0.2774 \\
& $170.4^{\mathrm{a}}$ & $-198.1^{\mathrm{a}}$ & $0.3162^{\mathrm{a}}$ \\
& $178.3^{\mathrm{b}}$ & $-193.6^{\mathrm{b}}$ & $0.3240^{\mathrm{b}}$ \\
\hline $\mathbf{9}$ & 118.5 & -197.6 & 0.2726 \\
& $144.6^{\mathrm{a}}$ & $-174.5^{\mathrm{a}}$ & $0.3118^{\mathrm{a}}$ \\
& $149.9^{\mathrm{b}}$ & $-169.1^{\mathrm{b}}$ & $0.3197^{\mathrm{b}}$ \\
\hline
\end{tabular}

a. The values are calculated in THF by PCM model.

b. The values are calculated in acetonitrile by PCM model.
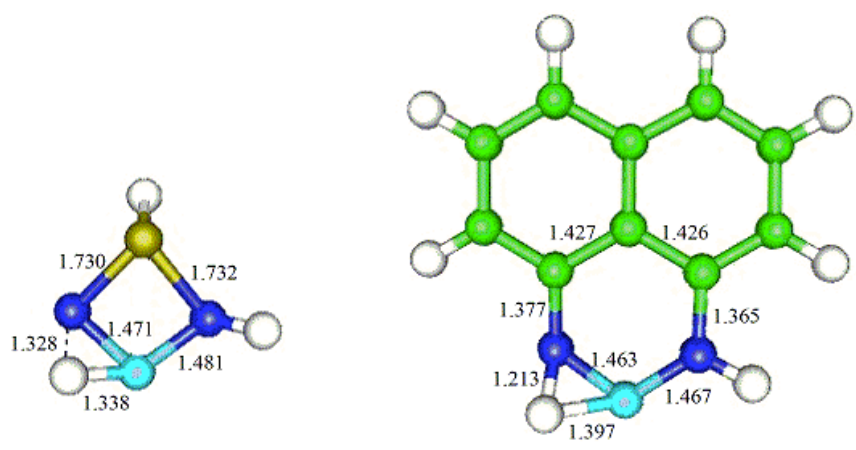

5-TS

6-TS

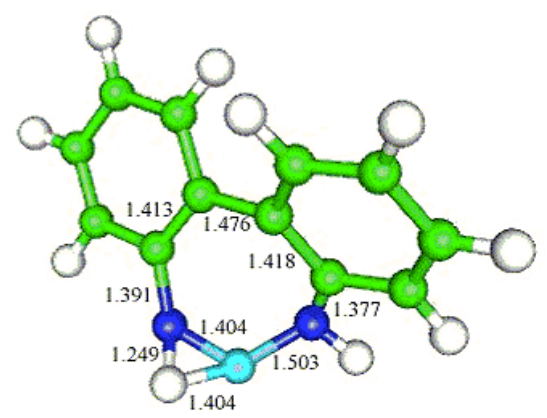

7-TS

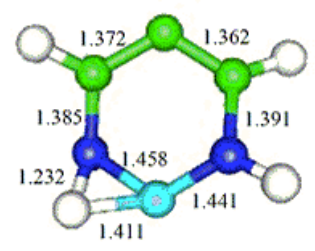

8-TS

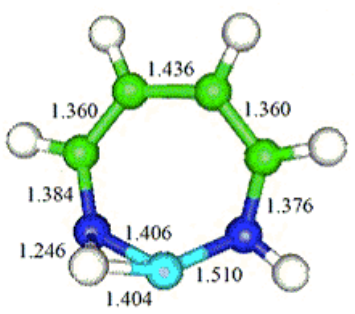

9-TS
Fig. (6). The critical geometrical parameters of TSs of the isomeriв and hydrogen in white).

Table 11. The $\Delta \sigma^{\text {iso }}$ on Boron (in ppm) of 5-9 and Their Isomerized Products

\begin{tabular}{|c|c|}
\hline & $\boldsymbol{\Delta \sigma}^{\text {isoa }}$ \\
\hline \hline $\mathbf{5}$ & -107.4 \\
\hline $\mathbf{5 - P r o d 1}$ & -32.86 \\
\hline $\mathbf{6}$ & -62.57 \\
\hline 6-Prod1 & -24.21 \\
\hline $\mathbf{7}$ & -98.29 \\
\hline 7-Prod1 & -26.75 \\
\hline $\mathbf{8}$ & -55.32 \\
\hline $\mathbf{8 - P r o d 1}$ & -22.75 \\
\hline $\mathbf{9}$ & -96.58 \\
\hline 9-Prod1 & -26.75 \\
\hline
\end{tabular}

a. The values are taken as $\sigma^{\text {iso }}$ of the compound $\sigma^{\text {iso }}$ of $\mathrm{BF}_{3}: \mathrm{OEt}_{2}$ 
sophisticated theoretical level [44]. According to our results, the titled boryl anions can spontaneously react with hydrogen gas to form dihydrogen adducts. For example, 1a reacts with $\mathrm{H}_{2}$, to form two new B-H bonds is a spontaneous reaction, by $\Delta \mathrm{G}=-146.0 \mathrm{~kJ} / \mathrm{mol}$. Applying Le Chatelier's principle, the equilibrium reaction may be shifted by pumping to remove $\mathrm{H}_{2}$. In other words, pressurizing with $\mathrm{H}_{2}$ will be useful in regenerating the $\mathrm{H}_{2}$ storage system. Moreover, this reaction can provide another method to investigate the relative stability between 1a and 3a. According to our calculation, the reaction free energy of $\mathbf{1 a}+\mathrm{H}_{2} \rightarrow \mathbf{3 a}$ is-35.44 $\mathrm{kJ} / \mathrm{mol}$, and this indicates that $1 \mathbf{a}$ reacts with $\mathrm{H}_{2}$ to form $\mathbf{3 a}$ spontaneously.

\section{CONCLUSIONS}

To sum up, several salient points can be noted according to our calculations on the boryl anions: (1) The bulkier, the $\mathrm{R}_{1}$ and $\mathrm{R}_{2}$ groups are, the more kinetically stable a fivemembered boryl anion may be. (2) Nitrogen should be the most efficient $\pi$ donor to stabilize a boryl anion, and the stability of a boryl anion increases as the number of nitrogen atom increases from a kinetic viewpoint. (3) A sixmembered boryl anion is predicted to be more kinetically stable than the five-membered one, that has been successfully synthesized $[4,6]$. (4) Similar to their isoelectronic analogues $\mathrm{N}$-heterocyclic carbenes, boryl anions could be good candidates to store hydrogen. Work focusing on the reactivity of nucleophilicities is in progress.

\section{ACKNOWLEDGEMENT}

We are grateful to the National Center for HighPerformance Computing of Taiwan, for allowing us generous amounts of computing time and the reviewers to provide their suggestions to prompt this manuscript. We also thank the National Science Council for financial support.

\section{REFERENCES}

[1] Auten RW, Kraus CA. Studies relating to boron. V. Chemistry of the dibutylboron group. J Am Chem Soc 1952; 74: 3398-401.

[2] Köster R, Benedikt G. 1-chloroborolanes. Angew Chem Int Ed Engl 1963; 2: 219 .

[3] Wagner M, van Eikema Hommes NJR, Nöth H, Schleyer PVR. Lithioboranes. A theoretical study. Inorg Chem 1995; 34: 607-14.

[4] Segawa Y, Yamashita M, Nozaki K. Boryllithium: isolation, characterization, and reactivity as a boryl anion. Science 2006; 314 : 113-5.

[5] Yamashita M, Suzuki Y, Segawa Y, Nozaki K. Synthesis, structure of borylmagnesium, and its reaction with benzaldehyde to form benzoylborane. J Am Chem Soc 2007; 129: 9570-1.

[6] Segawa Y, Yamashita M, Nozaki K. Boryl anion attacks transitionmetal chlorides to form boryl complexes: syntheses, spectroscopic, and structural studies on group 11 borylmetal complexes. Angew Chem Int Ed Engl 2007; 46: 6710 -3.

[7] Hartwig JF, Huber S. Transition metal boryl complexes: structure and reactivity of $\mathrm{CpFe}(\mathrm{CO}) 2 \mathrm{Bcat}$ and $\mathrm{CpFe}(\mathrm{CO}) 2 \mathrm{BPh} 2$. J Am Chem Soc 1993; 115: 4908 -9.

[8] Baker RT, Ovenall DW, Calabrese JC, et al. Boryliridium and boraethyliridium complexes fac-[IrH2( $\left.\left.\mathrm{PMe}_{3}\right)_{3}\left(\mathrm{BRR}^{\prime}\right)\right]$ and fac$\left.\left.\left[\mathrm{IrH}\left(\mathrm{PMe}_{3}\right)_{3} \text { (.eta.2- } \mathrm{CH}_{2} \mathrm{BHRR}\right)^{\prime}\right)\right]$. J Am Chem Soc 1990; 112: 9399400 .

[9] Kawano Y, Yasue T, Shimoi M. BH bond activation of trimethylphosphineborane by transition metal complexes: synthesis of metal complexes bearing nonsubstituted boryl-trimethylphosphine, $\mathrm{Cp} * \mathrm{M}(\mathrm{CO})_{3}\left(\mathrm{BH}_{2} \cdot \mathrm{PMe}_{3}\right)(\mathrm{M}=\mathrm{Mo}, \mathrm{W})$. J Am Chem Soc 1999; 121: 11744-50.
[10] Ito H, Kawakami C, Sawamura M. Copper-catalyzed $\gamma$-selective and stereospecific substitution reaction of allylic carbonates with biboron: efficient route to chiral allylboron compounds. J Am Chem Soc 2005; 127: 16034-5.

[11] Laitar, DS, Mueller P, Sadighi JP. Efficient homogeneous catalysis in the reduction of $\mathrm{CO}_{2}$ to CO. J Am Chem Soc 2005; 127: 171967.

[12] Arduengo III AJ, Harlow RL, Kline M. A stable crystalline carbene J Am Chem Soc1991; 113: 361-3.

[13] Enders D, Balensiefer T. Nucleophilic carbenes in asymmetric organocatalysis. Acc Chem Res 2004; 37: 534-41.

[14] Herrmann WA, Weskamp T, Böhm VPW. Metal complexes of stable carbenes. Adv Organomet Chem 2002; 48: 1-69.

[15] Despagnet-Ayoub E, Grubbs RH. A stable four-membered Nheterocyclic carbene. J Am Chem Soc 2004; 126: 10198-9.

[16] Bazinet P, Yap GPA, Richeson DS. Constructing a stable carbene with a novel topology and electronic framework. J Am Chem Soc 2003; 125: 13314-5.

[17] Scarborough CC, Grady MJW, Guzei IA, Gandhi BA, Bunel E E, Stahl SS. PdII complexes possessing a seven-membered Nheterocyclic carbene ligand. Angew Chem Int Ed 2005; 44: 526972.

[18] Frisch MJ, Trucks GW, Schlegel HB, et al. Gaussian 03, Revision D.01 Gaussian Inc.: Wallingford CT; 2004.

[19] Becke AD. Density-functional thermochemistry. III. The role of exact exchange. J Chem Phys 1993; 98: 5648-52.

[20] Zhao Y, Truhlar DG. Benchmark databases for nonbonded interactions and their use to test density functional theory. J Chem Theory Comput 2005; 1: 415-32.

[21] Slanina Z, Pulay P, Nagase S. H2, Ne, and N2 energies of encapsulation into C60 Evaluated with the MPWB1K Functional. J Chem Theory Comput 2006; 2: 782-5.

[22] Lynch BJ, Fast PL, Harris M, Truhlar DG. Adiabatic connection for kinetics. J Phys Chem A 2000; 104: 4811-5.

[23] McWeeny R. Perturbation theory for the fock-dirac density matrix. Phys Rev 1962; 126: 1028-34.

[24] Miertus S, Scrocco E, and Tomasi J, Electrostatic interaction of a solute with a continuum. A direct utilizaion of ab initio molecular potentials for the prevision of solvent effects. Chem Phys 1981; 55: 117-29.

[25] Metzler-Nolte N. Ab initio study of Arduengo-type group 13 carbene analogues. New J Chem 1998; 22: 793-5.

[26] Sundermann A, Reiher M, Schoeller WW. Isoelectronic Arduengotype carbene analogues with the group IIIa elements boron, aluminum, gallium, and indium. Eur J Inorg Chem 1998; (3): 305-10.

[27] Miller AR. A theoretical relation for the position of the energy barrier between initial and final states of chemical reactions. J Am Chem Soc 1978; 100: 1984-92.

[28] Lai CH, Li EY, Chen KY, Chow TJ, Chou PT. Theoretical investigation of cheletroptic decarbonylation reactions. J Chem Theory Comput 2006; 2: 1078-84

[29] Matsumi N, Naka K, Chujo Y. Extension of $\pi$-conjugation length via the vacant $\mathrm{p}$-orbital of the boron atom. Synthesis of novel electron deficient $\pi$-conjugated systems by hydroboration polymerization and their blue light emission. J Am Chem Soc 1998; 120: 5112-3.

[30] Cheng MJ, Hu CH. A computational study on the stability of diaminocarbenes. Chem Phys Lett 2000; 322: 83-90.

[31] Dinadayalane TC, Geetha K, Sastry GN. Ab initio and density functional theory (DFT) study on [1,5] Sigmatropic Rearrangements in pyrroles, phospholes, and siloles and their Diels-Alder reactivities. J Phys Chem A 2003; 107: 5479-87.

[32] Regitz M. Stable carbenes-Illusion or reality. Angew Chem Int Ed Engl 1991; 30: 674-6.

[33] West R. Japan Bats a Triple. Science 2004; 305: 1724-5.

[34] Hammond GS. A Correlation of Reaction Rates. J Am Chem Soc 1955; 77: 334-8.

[35] Dixon DA, Arduengo III AJ. Electronic structure of a stable nucleophilic carbene. J Phys Chem 1991; 95: 4180-2.

[36] Arduengo III AJ, Dias HVR, Dixon DA, Harlow RL, Klooster WT, Koetzle TF. Electron distribution in a stable carbene. J Am Chem Soc 1994; 116: 6812-22.

[37] Arduengo III AJ, Dixon DA, Kumashiro KK, Lee C, Power WP, Zilm KW. Chemical Shielding Tensor of a Carbene. J Am Chem Soc 1994; 116: 6361-7. 
[38] Arduengo III AJ, Bock H, Chen H, et al. Photoelectron Spectroscopy of a Carbene/Silylene/Germylene Series. J Am Chem Soc 1994; 116: 6641-9.

[39] Heinemann C, Thiel W. Ab initio study on the stability of diaminocarbenes. Chem Phys Lett 1994; 217: 11-16.

[40] Arduengo III AJ, Goerlich JR, Marshall WJ. A stable diaminocarbene. J Am Chem Soc 1995; 117: 11027-8.

[41] Del Bene JE, José Elguero J, Alkorta I, Yáñez M, Mó O. Attacking Boron Nucleophiles: NMR Properties of Five-Membered Diazaborole Rings. J Phys Chem A 2007; 111: 419-21.
[42] Kastrup CJ, Oldfield SV, Rzepa HS. An ab initio computational study of monodentate palladium ligand complexes with Möbiusaromatic chiral character. J Chem Soc Dalton Trans 2002; 12: 2421-2

[43] Kastrup CJ, Oldfield SP, Rzepa HS. The aromaticity and Möbius characteristics of carbeno[8]heteroannulenes and triplet state annulenes. Chem Commun 2002; 6: 642-3.

[44] Dixon DA, Arduengo III AJ. Accurate heats of formation of the "Arduengo-type" carbene and various adducts including $\mathrm{H}_{2}$ from ab initio molecular orbital theory. J Phys Chem A 2006; 110: 196874.

Received: December 13, 2007

Revised: May 12, 2008

Accepted: May 13, 2008

(C) Zhou et al.; Licensee Bentham Open.

This is an open access article distributed under the terms of the Creative Commons Attribution License (http://creativecommons.org/licenses/by/2.5/), which permits unrestrictive use, distribution, and reproduction in any medium, provided the original work is properly cited. 